\title{
Analysis of The Simulation of The Water Supply Network of The New City of Guelma by Epanet
}

\section{Kherouf Mazouz, Baout Abdelraouf}

Laboratory of Civil Engineering and Hydraulics, University of 8 May 1945.

*Corresponding Author Email: kherouf.mazouz@univ-guelma.dz

\section{DOI: 10.2478/pjg-2021-0005}

\section{Abstract:}

Forecasting and monitoring the parameters of a drinking water network such as flow, pressure and quality are essential issues for the operator in order to guarantee a compliant distribution at all times. Water leaks are the main problem in the management of drinking water networks, so a drinking water network must be reliable and sustainable to meet the needs of subscribers. The modeling of a network allows, among other things, to determine distribution strategies in order to guarantee continuous quality of service. The EPANET modeling software, developed by the US Environmental Protection Agency, enables the hydraulic and quality behavior of a water distribution network to be simulated on the basis of its parameters. Our work consists of simulating an existing network in the new city of Guelma in order to check all the necessary elements of the network, namely pressure, speed, flow and water quality. The results obtained verified that the pressure at all junctions and the flow rates with their velocities at all mains is sufficiently feasible to supply adequate water to the network in the study area. These results will help to better understand the pipeline network in the Study Area and allow the Study Area to be studied in the future.

\section{Keywords: pressure, quality, velocity, Guelma, simulation, EPANET}

\subsection{Introduction}

The hydraulic analysis of the distribution network consists of proposing an orientation for efficient maintenance, control of flows and pressures within the drinking water supply network, as well as the implementation of a system allowing a reasonable supply of water and the satisfaction of future needs $[1,2]$. These models are called analytical models. When the system is complex enough to model analytically, practitioners use a descriptive model that details the various events and actions that describe its behavior [3]. To know the hydraulic functioning of the network over the current and future horizons and also to estimate the needs for reinforcement and extension of the network in terms of infrastructure [4], to obtain a vision of the functioning of the network in any condition at the desired degree of accuracy. This makes it possible to determine the faults and black spots not apparent on our network, which would be the basis for drawing up short- and long-term management and reinforcement schedules $[5,6]$

Calculating flows and pressures in a complex network has been a great challenge and interest for those involved in the design, construction and maintenance of public water distribution systems. The analysis and design of piping networks creates a relatively complex problem, especially if the network consists of a series of pipes, as is often the case in water distribution systems in large urban areas. In the absence of a significant amount of accelerating fluid, the behavior of a network can be determined by a sequence of equilibrium conditions, which constitute a small but essential part of the assessment of the adequacy of a network [7]. Such an analysis is necessary whenever changes in consumption or delivery patterns are significant or, with the addition of features such as water supply, booster pumps, pressure control valves or storage tanks, modify the system. Many methods have been used in the past to calculate flows in a piping system, ranging from graphical methods to the use of analogies and finally to the use of mathematical models [7 8]. The complexity of drinking water networks and the difficulty for managers to predict the hydraulic phenomena taking place in them make computerized management indispensable, made possible by advances in computer technology $[9,10]$.

\section{Indeed, it allows:}

\section{- To improve knowledge of the networks which are the subject of such a study;}

- Detect and understand the problems that can occur in the network: for example, we can locate areas where the pressure is abnormal and deduce the presence of leaks or the existence of unknown elements, realize that the theoretical operating times of the pumps are much shorter than the measured times, or discover other clues that indicate a malfunction;

- Simulate the behavior of the network over a period of at least one day in order to optimize resources, storage capacity and pumping;

- Study the impact of new consumption or possible incidents, forecasting and adapting facilities to cope with new constraints or crisis situations;

- Sizing extensions, reinforcements or developments required to meet new needs.

\subsection{Description of the network of the new city of Guelma (south land use plan)}

The network of south land use plan is a meshed network and the supply of the subscribers of this city is done by gravitation from an SP4 accumulation tank. This SP4 reservoir has a capacity of $1500 \mathrm{~m}^{3}$ located at an altitude of $459 \mathrm{~m}$. The main length of the south land use plan network is $6441.71 \mathrm{~m}$ and $8876.00 \mathrm{~m}$ for the secondary pipelines, representing a total network length of around $15.31771 \mathrm{~km}$ (Figure 1). Note the presence of 18 nodes in the distribution, node 1 is the highest at $441 \mathrm{~m}$ while node 15 is the lowest with an altitude of $358.52 \mathrm{~m}$ (Table 1 ). Thus, we obtain an author altitude difference of $82.48 \mathrm{~m}$. It can be noted that there are 22 distribution pipes and one adduction pipe, there is a master pipe of great length $20 \mathrm{~km}$, and the others are between $83 \mathrm{~m}$ and $515 \mathrm{~m}(83 \mathrm{~m} \leq \mathrm{L} \leq 515 \mathrm{~m})$.

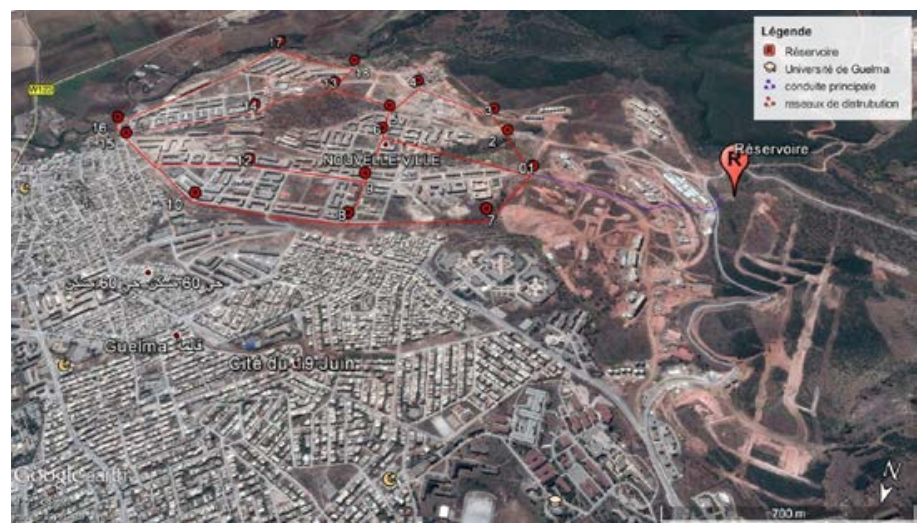

Figure 1: New city Guelma (south POS) 
Table 1: Status of the Nodes of the Network

\begin{tabular}{|c|c|c|}
\hline Node ID & Elevation (m) & $\begin{array}{c}\text { base demand } \\
(1 / \mathrm{s})\end{array}$ \\
\hline Junk 1 & 417 & 9.73 \\
\hline Junk 2 & 414.5 & 2.1 \\
\hline Junk 3 & 441 & 4.32 \\
\hline Junk 4 & 419.5 & 5.01 \\
\hline Junk 5 & 396.3 & 5.66 \\
\hline Junk 6 & 389.9 & 7.68 \\
\hline Junk 7 & 402 & 8.81 \\
\hline Junk 8 & 382.5 & 10.76 \\
\hline Junk 9 & 404.45 & 5.44 \\
\hline Junk 10 & 381.5 & 7.04 \\
\hline Junk 11 & 379.5 & 9.06 \\
\hline Junk 12 & 400 & 4.47 \\
\hline Junk 13 & 391 & 8.97 \\
\hline Junk 14 & 367.65 & 5.45 \\
\hline Junk 15 & 358.52 & 5.63 \\
\hline Junk 16 & 358.57 & 6.46 \\
\hline Junk 17 & 378.68 & 6.13 \\
\hline Junk 18 & 382 & 3.8 \\
\hline Junk 20 & 359 & 0 \\
\hline water tank 21 & 350 & No value \\
\hline Tank 19 & 459 & No value \\
\hline
\end{tabular}

Table 2: Status of the Arcs of the Network

\begin{tabular}{|c|c|c|c|}
\hline Link ID & $\begin{array}{l}\text { Length } \\
\text { (m) }\end{array}$ & $\begin{array}{l}\text { Diameter } \\
(\mathrm{mm})\end{array}$ & Hazen Williams coefficient \\
\hline Pipe 1 & 83 & 250 & 115 \\
\hline Pipe 2 & 121 & 250 & 115 \\
\hline Pipe 3 & 299 & 250 & 115 \\
\hline Pipe 4 & 188 & 200 & 115 \\
\hline Pipe 5 & 111 & 150 & 115 \\
\hline Pipe 7 & 347 & 200 & 115 \\
\hline Pipe 8 & 509 & 200 & 115 \\
\hline Pipe 9 & 232 & 150 & 115 \\
\hline Pipe 10 & 121 & 150 & 115 \\
\hline Pipe 11 & 304 & 150 & 115 \\
\hline Pipe 12 & 380 & 100 & 115 \\
\hline Pipe 13 & 259 & 100 & 115 \\
\hline Pipe 14 & 176 & 100 & 115 \\
\hline Pipe 16 & 308 & 100 & 115 \\
\hline Pipe 18 & 242 & 100 & 115 \\
\hline Pipe 19 & 318 & 100 & 115 \\
\hline Pipe 20 & 51 & 100 & 115 \\
\hline Pipe 21 & 544 & 100 & 115 \\
\hline Pipe 22 & 84 & 100 & 115 \\
\hline Pipe 23 & 347 & 350 & 115 \\
\hline Pipe 24 & 2000 & 400 & 115 \\
\hline Pipe 17 & 221 & 100 & 115 \\
\hline Pipe 6 & 515 & 200 & 115 \\
\hline Pipe 15 & 245 & 150 & 115 \\
\hline
\end{tabular}




\subsection{Simulation by EPANET}

The result of the EPANET software simulation gave the following result:

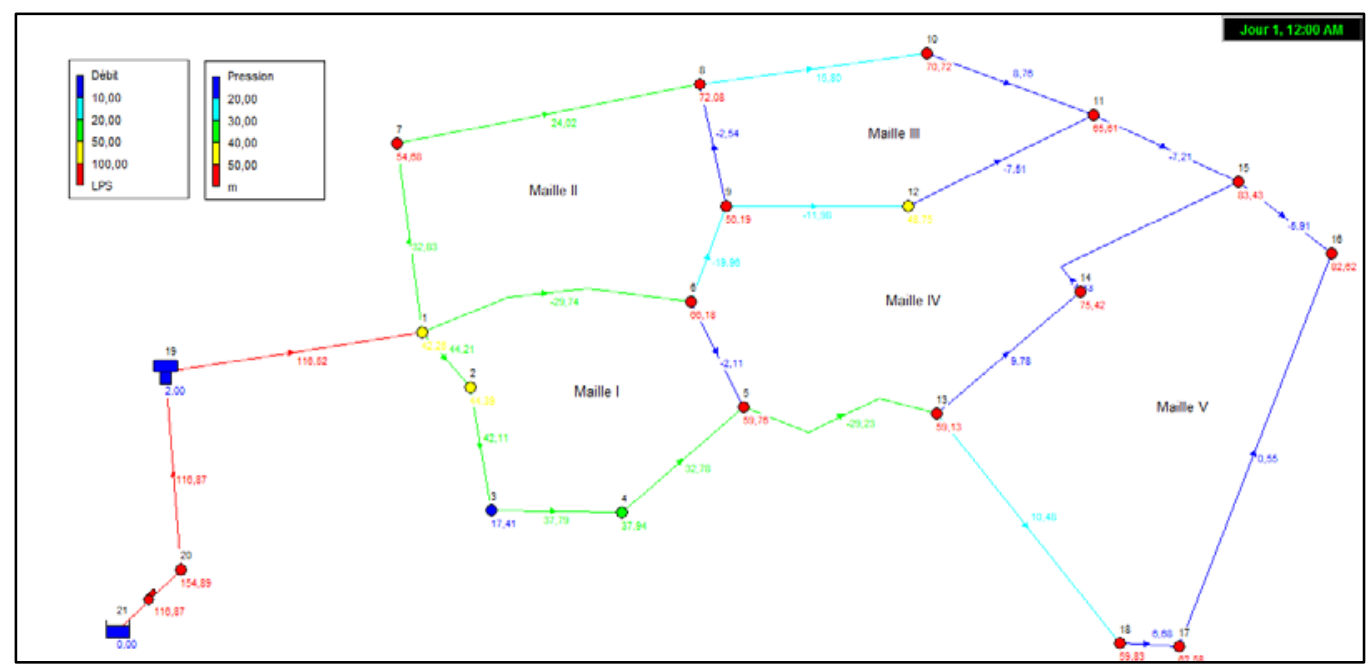

Figure 2: Variation in pressure and flow rate

The pressure distribution is shown in graph3.

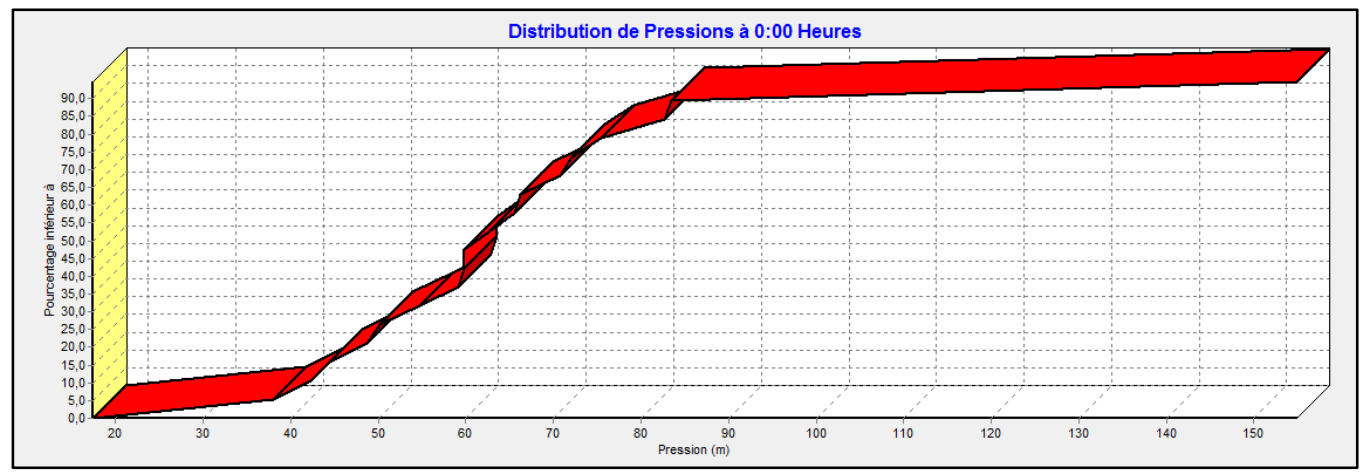

Figure 3: Pressure distributions at 0.00 hour

There are three slices:

Slice 1: between 0 and $40 \mathrm{~m}$ it has $10 \%$ of the total pressure.

Slice 2: between 40 and $75 \mathrm{~m}$ it presents $75 \%$ of the total pressure.

Slice 3: between 75 and $100 \mathrm{~m}$ it presents $15 \%$ of the total pressure.

\subsection{Synthesis and interpretation}

The first value of the pressure is zero because it is the beginning of the filling of the pipes. A pressure percentage of $75 \%$ between is between 40 and $75 \mathrm{~m}$, as these nodes are close to the supply tank.

A pressure percentage of $15 \%$ is higher than $40 \mathrm{~m}$ because these last points are at low elevations in relation to the reservoir because the pressure becomes important as soon as there is a significant difference in altitude.

The hypotheses retained for the modeling of the network are the following:

- Minimum acceptable pressure at the subscriber's premises: 1 to 4 bars.

- Maximum speed in the pipes: $1.5 \mathrm{~m} / \mathrm{s}$.

\subsection{Guide values for correct operation}

- Pressures must be between 2 and 4 bars.

- The flow velocity of the water in the pipes must be between 0.5 and $1.25 \mathrm{~m} / \mathrm{s}$.

- Chlorine concentration in nodes and pipes must be greater than $0.1 \mathrm{mg} / \mathrm{l}$ and not exceed $2.00 \mathrm{mg} / \mathrm{l}$.

\subsection{Results of the network modelling}

Flow rate: $2.1 \mathrm{l} / \mathrm{s} \leq \mathrm{Q} \leq 116.52 \mathrm{l} / \mathrm{s}$.

Except for the flow rate of the 21st pipe which is very low $(0.55 \mathrm{l} / \mathrm{s})$.

The speed: $0,12 \mathrm{~m} / \mathrm{s} \leq \mathrm{V} \leq 1.65 \mathrm{~m} / \mathrm{s}$.

Except for the speed of the 21st pipe which is very low $(0.07 \mathrm{~m} / \mathrm{s})$. 


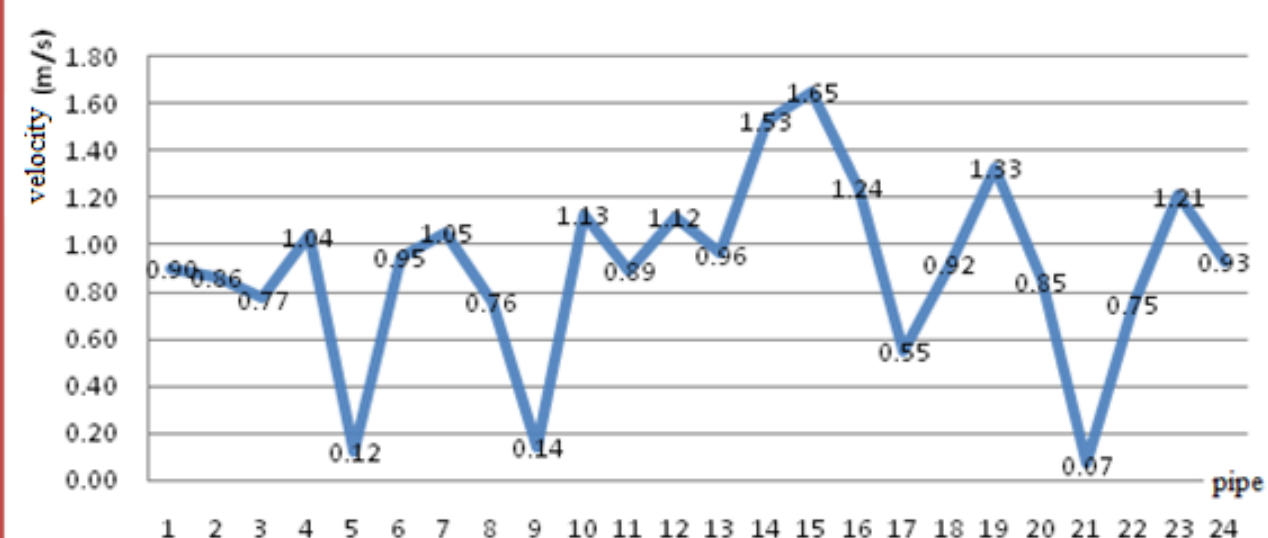

Figure 4: Variation curve of the flow velocity in the network

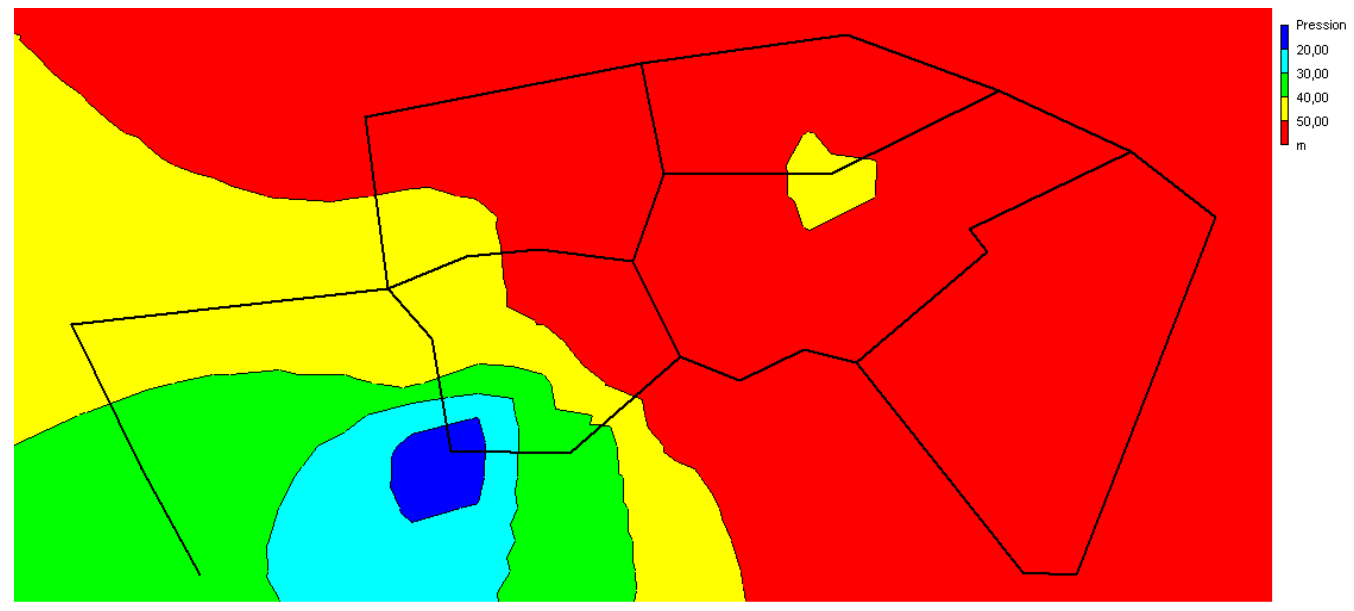

Figure 5: Pressure level curve 0:00 hours

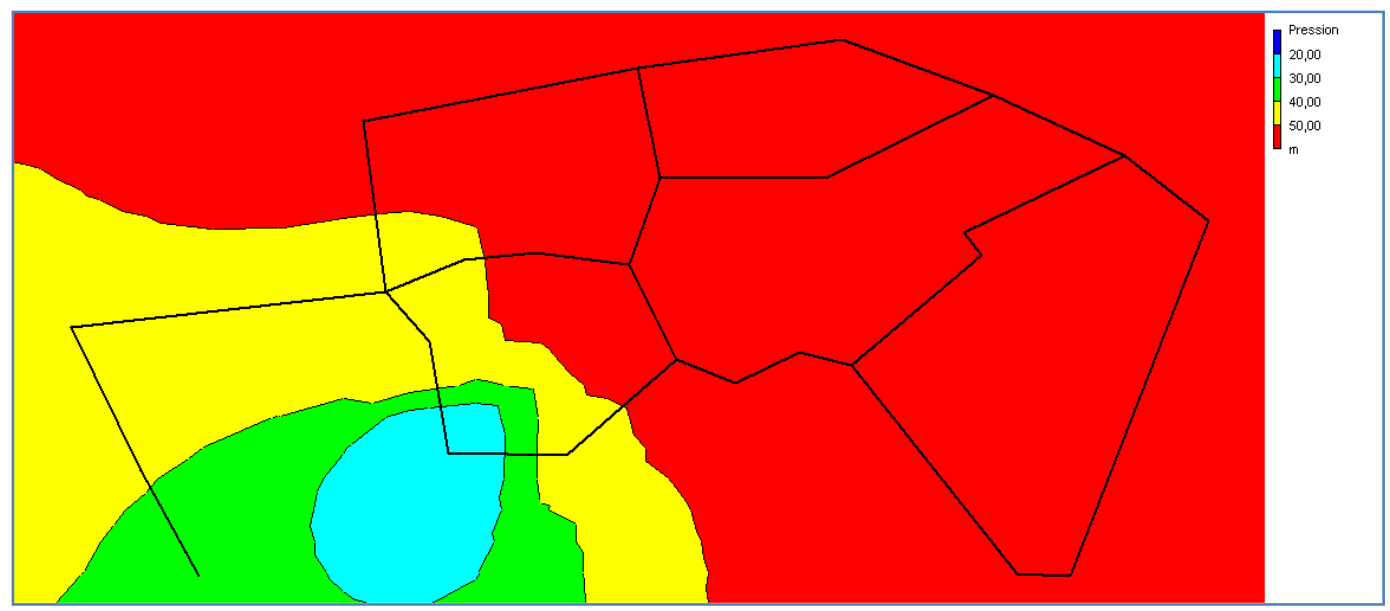

Figure 6: Pressure level curve 71:00 hours

You can see the variation of the pressure level curves between 0:00 hours and 0:00 hours.

71:00 hours (figure 5 and figure 6 ) it can be seen that the pressure is at its highest during the night period.

Figure 7 shows the pressure evolution for nodes 1 to 6 as a function of the pipe distance. 


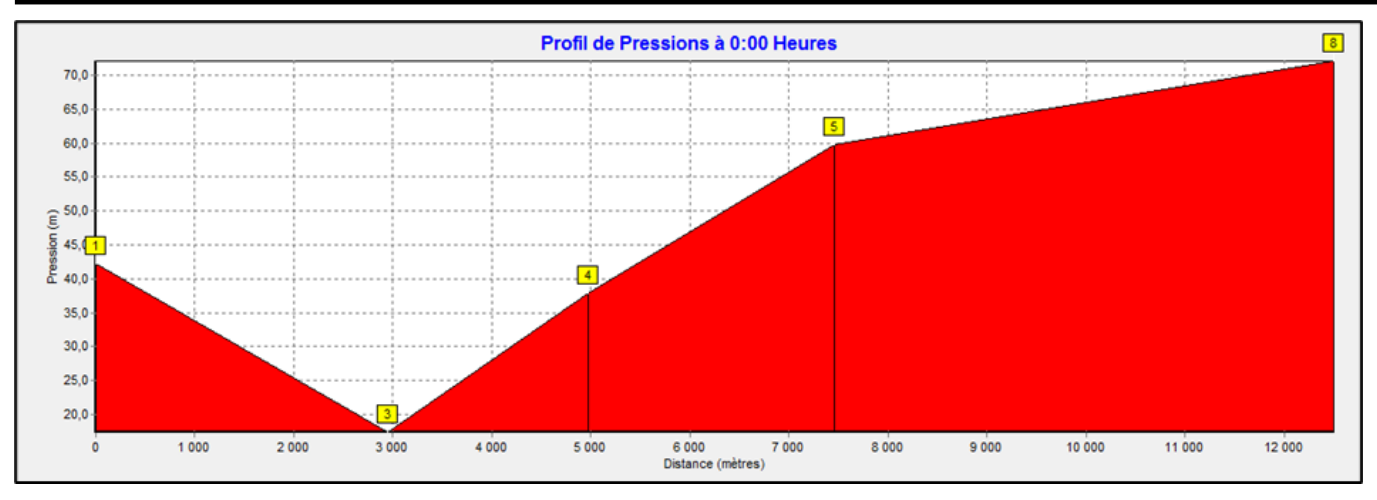

Figure 7: Pressure profile of the nodes $(1,3,4,5$, and 6$)$

Once the network is defined by all these data (see table), i.e. the characteristics and condition of the pipes. The simulation by EPANET gives the following table of results:

Table 3: Status of the Arcs of the Network 8:00 Hours

A-Table of nodes:

\begin{tabular}{|c|c|c|c|c|c|}
\hline Macs. & & & & & \\
\hline ID Junk & Elevation (m) & Demand (l/s) & Head (m) & Pressure (m) & Chlore (mg/l) \\
\hline Junk 1 & 417 & 9.73 & 459.25 & 42.25 & 0.96 \\
\hline Junk 2 & 414.5 & 2.1 & 458.89 & 44.39 & 0.94 \\
\hline Junk 3 & 441 & 4.32 & 458.42 & 17.42 & 0.91 \\
\hline Junk 4 & 419.5 & 5.01 & 457.47 & 37.97 & 0.88 \\
\hline Junk 5 & 396.3 & 5.66 & 456.11 & 59.81 & 0.86 \\
\hline Junk 6 & 389.9 & 7.68 & 456.11 & 66.21 & 0.92 \\
\hline Junk 7 & 402 & 8.81 & 456.73 & 54.73 & 0.93 \\
\hline Junk 8 & 382.5 & 10.76 & 454.68 & 72.18 & 0.87 \\
\hline Junk 9 & 404.45 & 5.44 & 454.68 & 50.23 & 0.9 \\
\hline Junk 10 & 381.5 & 7.04 & 452.33 & 70.83 & 0.84 \\
\hline Junk 11 & 379.5 & 9.06 & 445.25 & 65.75 & 0.83 \\
\hline Junk 12 & 400 & 4.47 & 448.83 & 48.83 & 0.87 \\
\hline Junk 13 & 391 & 8.97 & 450.22 & 59.22 & 0.83 \\
\hline Junk 14 & 367.65 & 5.45 & 443.31 & 75.66 & 0.8 \\
\hline Junk 15 & 358.52 & 5.63 & 442.26 & 83.74 & 0.78 \\
\hline Junk 16 & 358.57 & 6.46 & 441.54 & 82.97 & 0.69 \\
\hline Junk 17 & 378.68 & 6.13 & 441.38 & 62.7 & 0.77 \\
\hline Junk 18 & 382 & 3.8 & 441.95 & 59.95 & 0.8 \\
\hline Junk 20 & 359 & 0 & 471.02 & 112.02 & 1 \\
\hline water tank 21 & 350 & -165.05 & 350 & 0 & 1 \\
\hline Tank 19 & 459 & 48.53 & 461 & 2 & 0.97 \\
\hline
\end{tabular}

Table 4: State of the Arcs of the Network at 8:00 a.m

B-Table of pipes

\begin{tabular}{|c|c|c|c|c|c|}
\hline & Elevation $(\mathrm{m})$ & Base demand $(\mathrm{l} / \mathrm{s})$ & Unit Head loss $(\mathrm{m} / \mathrm{Km})$ & Pressure $(\mathrm{m})$ & Chlore $(\mathrm{mg} / \mathrm{l})$ \\
\hline ID Junk & 417 & 9.73 & 459.25 & 42.25 & 0.96 \\
\hline Junk 1 & 414.5 & 2.1 & 458.89 & 44.39 & 0.94 \\
\hline Junk 2 & 441 & 4.32 & 458.42 & 17.42 & 0.91 \\
\hline Junk 3 & 419.5 & 5.01 & 457.47 & 37.97 & 0.88 \\
\hline Junk 4 & 396.3 & 5.66 & 456.11 & 59.81 & 0.86 \\
\hline Junk 5 & 389.9 & 7.68 & 456.11 & 66.21 & 0.92 \\
\hline Junk 6 & 402 & 8.81 & 456.73 & 54.73 & 0.93 \\
\hline Junk 7 & 382.5 & 10.76 & 454.68 & 72.18 & \\
\hline Junk 8 & 404.45 & 5.44 & 454.68 & 50.23 & 0.87 \\
\hline Junk 9 & 381.5 & 7.04 & 452.33 & 70.83 & 0.83 \\
\hline Junk 10 & 379.5 & 9.06 & 445.25 & 65.75 & 0.87 \\
\hline Junk 11 & 400 & 4.47 & 448.83 & 48.83 & 0.83 \\
\hline Junk 12 & & & & 0.87 \\
\hline
\end{tabular}




\begin{tabular}{|c|c|c|c|c|c|}
\hline & 391 & 8.97 & 450.22 & 59.22 & 75.66 \\
\hline Junk 13 & 367.65 & 5.45 & 443.31 & 83.74 & 0.83 \\
\hline Junk 14 & 358.52 & 5.63 & 442.26 & 82.97 & 0.78 \\
\hline Junk 15 & 358.57 & 6.46 & 441.54 & 62.7 & 0.69 \\
\hline Junk 16 & 378.68 & 6.13 & 441.38 & 59.95 & 0.77 \\
\hline Junk 17 & 382 & 3.8 & 441.95 & 112.02 & 0.8 \\
\hline Junk 18 & 359 & 0 & 471.02 & & 1 \\
\hline
\end{tabular}

Analysis of the table of simulation results shows that:

Flow rate: the flow rates obtained are in the range of: $2.1 \mathrm{l} / \mathrm{s} \leq \mathrm{Q} \leq 116.52 \mathrm{l} / \mathrm{s}$. It should be noted that the flow rates are very low, so in practice the diameter of these pipes must be reduced in order to have an acceptable speed.

\subsection{The speed of the Chlorine reaction}

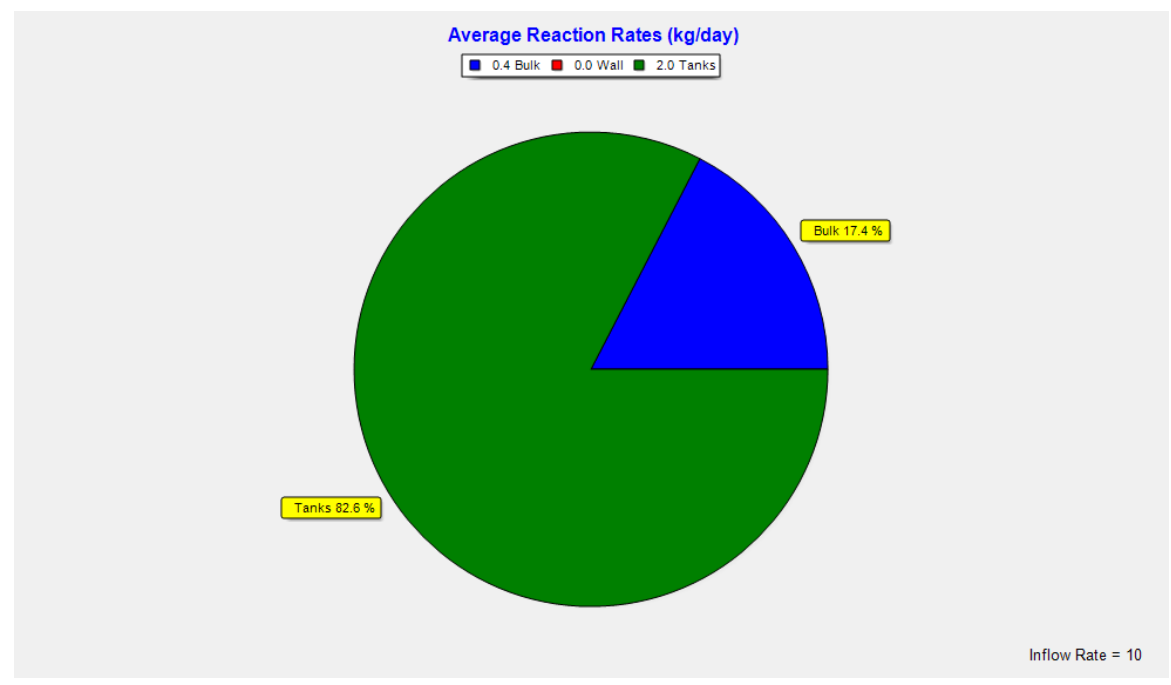

Figure 7: Average reaction rates

The quality analysis showed that the average distribution of chlorine losses in the pipes and in the tank. It should be noted that the term mass refers to the reactions that take place in the mass of the fluid, while the term wall refers to the reactions with the walls of the pipes. The latter reaction is nil because we have not indicated a wall reaction coefficient in our case.

\subsection{Conclusion}

It should be noted that the node pressures and velocities in the pipelines of the existing network in the study area are acceptable. A few nodes have values greater than $70 \mathrm{~m}$ and require pressure reducing valves. Some pipes have been oversized because the velocity is very low, so we recommend changing the diameter. The EPANET simulation can also give us information on the behaviour of the network in case of pipe ruin and from this we can launch the simulation of this scenario in order to take this case into account and consequently this simulation allows us to make decisions on the behaviour of the network. Also we can introduce the flow rate of $17 \mathrm{l} / \mathrm{s}$ into the network at certain points susceptible to fire in order to verify that the network is fireproof.

\subsection{References}

[1] P. Lina, H. Mashor, and O. Avi, "Robust optimization for water distribution systems least cost designs”, Water Resources Research, Vol. 49, No. 10, Pp. 6795-6809, 2013.

[2] E. Jakobus, V. Zyl, Y. le Gat, P. Olivier and T.M. Walski, "Impact of water demand parameters on the reliability of municipal storage tanks", Journal of Water Ressources Planning and Management- ASCE, Vol. 138, No. 5, Pp. 553-561, 2012.

[3] P. Eisenbies, C. Werey, and C. Laplaud, "L'enregistrement des défaillances pour améliorer la connaissance des réseaux d'eau potable », Techniques Sciences Méthodes, $\mathrm{N}^{\circ} 6$ - p 42-54, 2002.

[4] E. Alperovits, and U. Shamir, "Design of optimal water distribution systems”, Water Resources Research, Vol. 13, No. 6, Pp. 885-900, 1977.

[5] EPANET, Water research, US EPA, 2008. https://www.epa.gov/water-research/epanet

[6] L. Rossman, “EPANET 2 Users Manual”, U.S. Environmental Protection Agency, 600/R-00/057, Cincinnati, OH, 2000.

[7] American Water Works Association, Analysis, and Design of Water Distribution Systems.

[8] AWWA. M32- Computer Modelling of Water Distribution Systems. Denver, CO., Pp. 159, 2005.

[9] B. Choux, «Modélisation des réseaux d'eau potable, compatibilité avec la cartographie informatisée » , L’eau - L'industrie - Les nuisances №141, pp. 48 $-50,1990$.

[10] F. Valiron, «Mémento du gestionnaire de l'alimentation en eau potable et de l'assainissement », Tome 1, 2, 3, Edition Lavoisier, Pp. $1262,1994$. 